\title{
Assessing the welfare impacts of shared mobility and Mobility as a Service (MaaS)
}

\section{Working Paper}

\section{Author(s):}

Becker, Henrik; Balać, Miloš; Ciari, Francesco; Axhausen, Kay W. (D)

Publication date:

2018-08

Permanent link:

https://doi.org/10.3929/ethz-b-000286485

Rights / license:

In Copyright - Non-Commercial Use Permitted

Originally published in:

Arbeitsberichte Verkehrs- und Raumplanung 1378 


\title{
Assessing the welfare impacts of Shared Mobility and Mobility as a Service (MaaS)
}

\author{
Henrik Becker ${ }^{\mathrm{a}, *}$, Milos Balac ${ }^{\mathrm{a}}$, Francesco Ciari $^{\mathrm{b}}$, Kay W. Axhausen ${ }^{\mathrm{a}}$ \\ ${ }^{a}$ Institute for Transport Planning and Systems, ETH Zurich, 8093 Zurich, Switzerland \\ ${ }^{b}$ LIFE Centre for Climate, Energy and Society, Joanneum Research, 8020 Graz, Austria
}

\begin{abstract}
Mobility as a Service (MaaS) aims to allow less biased mode choice decisions by overcoming market segmentation. To this end, all available modes are offered at their respective marginal cost for each trip. Such a setting favors shared modes, where fixed costs can be apportioned among a large number of users. In turn, car-sharing, bike-sharing or ridehailing may themselves become an efficient alternative of public transport. Although early field studies confirm the expected changes in behaviour, impacts have not been studied for larger transport systems yet. This research conducts a first joint simulation of car-sharing, bike-sharing and ride-hailing for a city-scale transport system using MATSim. Results show that in Zurich, through less biased mode choice decisions, transportrelated energy consumption can be reduced by $25 \%$. In addition, introduction of shared modes may increase transport system efficiency by up to $7 \%$. Efficiency gains may reach $11 \%$ if shared modes were used as a substitute for public transport in lower-density areas. Hence, a MaaS scheme with shared mobility allows to increase system efficiency (travel times \& cost), while substantially reducing energy consumption.
\end{abstract}

Keywords: Mobility as a Service, car-sharing, bike-sharing, ride-hailing, ride-sourcing, taxi, energy consumption, welfare, MATSim

\footnotetext{
* Corresponding author

Email address: henrik.becker@ivt.baug.ethz.ch (Henrik Becker)
}

Preprint submitted to Transportation Research Part A 


\section{Introduction}

In current transport systems, short-term travel behaviour is to a large extent governed by long-term choices of mobility tool ownership. Such mobility tools usually require a substantial investment up-front and subsequently allow to travel with the specific modes 5 at low (or zero) marginal cost. Eventually, distinct mobility portfolios arise dividing a population into car drivers and transit riders [1]

The concept of Mobility as a service (MaaS) aims to break the determining role of mobility tool ownership in favour of a pay-per-use approach 18. Translating fixed (sunk)

10 costs into marginal costs allows for a more time- and cost-aware travel behaviour - an observation already made for early car-sharing customers 2. More recently launched shared mobility services already point into this direction: Uber, Bridj, car2go as well as many others do not charge membership fees, but follow a pay-per-use approach, but it is unknown, if they currently charge their average cost per $\mathrm{km}$ (including overheads and 15 profit margins).

In the past years, there were first attempts to transfer this concept to private cars and public transport, and thus turn travellers into mobility consumers. For example, [3, 4. conducted a six-month field test in the city of Gothenburg, Sweden, in which partici-

20 pants could purchase a monthly credit for the use of individual cars, car-sharing and public transport. Using one-week travel diaries, they show that participants generally over-estimated their actual travel demand and that as MaaS users, they would substantially reduce their use of individual cars and increase their use of public transport instead.

25 However, it is still unclear how to re-design a whole transport system to reap these benefits of MaaS shown in the small-scale field tests. In particular, this will require changes in the supply side of the system, i.e. restructuring public transport services 5 and integrating them with novel systems of shared mobility [6]. On the demand side, the first insights from field tests have to be generalized to learn more about the preferences of

30 travellers in such integrated mobility systems [7. Indeed, differences observed between Uber riders and taxi customers or users of different car-sharing schemes indicate that even small changes in the service types may attract different customer segments [8, 9].

Following the approach suggested by [10, in this research, a framework to assess the im35 pact of supply side characteristics of a potential MaaS scheme on the transport network is developed. Variables include type and fleet sizes of shared modes, their integration with public transport and additional taxes on car travel. Target indicators are generalized cost (welfare) measures, total network travel times and total energy consumption. The framework is applied to the city of Zurich, Switzerland. 


\section{Background}

For almost a century, private cars have dominated transport systems in industrialzied countries around the globe, by far outnumbering any form of collective transportation. A main reason for this (among various others) is that accessibility levels by public transport are usually substantially lower than those by car - even in Switzerland, which arguably

45 has one of the best public transport offerings worldwide, there is a $35 \%$ difference [11. Whilst in dense cities, bundling passengers in buses or trains allows to increase system capacity [12], such bundling is not feasible in low-density neighborhoods or countrysides and usually results in long headways and/or stop-spacing. In such situations, demandresponsive transit services 13 may help to extend public transport networks, although

50 no large-scale implementations have been tested yet.

In recent years, numerous new mobility services have emerged, such as bike-sharing [14], car-sharing [15] or ride-hailing services like Uber. They mostly operate in urban areas and often attract public transport users, thus having a potential of extending pub-

55 lic transport networks by offering last-mile connections [16] or fast tangential trips [17. However, currently, most such schemes are operated independently from each other and from collective transportation, so that reaping such benefits cannot be guaranteed.

MaaS aims to combine existing modes of collective transportation with such emerg-

60 ing services to establish a more attractive alternative to the private car [18]. A twofold integration will be required to achieve this aim:

- integrated strategic and operational planning across all mobility services (i.e. network / service areas, fleet sizes, fare integration),

- integrated user interface, through which all services can be accessed and booked.

${ }_{65}$ While the first part is obviously required to offer seamless mobility solutions, the second part allows travelers to make informed (and therefore better) decisions.

Sochor et al. 3, 4] conducted a first field test of a MaaS scheme with an emphasis on the second part (integrated user interface). In their study, participants purchased credit for the use of different mobility services, which they could then book through a unified service center. The results indicate that participants typically over-estimated their need for private car use. This is in line with an observation made for car-sharing customers, who often switched to a public transport lifestyle and use car-sharing vehicles for far less trips than they previously used their car for [2]. Such observations point at

75 one key behavioral implication of MaaS: Current transport modes are typically dominated by fixed costs [1, 19], so that acquisition of a mobility tool often predetermines later mode choice (because of the low marginal costs). MaaS overcomes the separation of fixed (sunk) and marginal costs by a pay-per-use approach. This way, it enables travelers to take unbiased and hence, more suitable mode choice decisions.

Yet, the user interface and cost truth are only one way, in which MaaS contributes to a more efficient transport system. The second way lies in a supply-side integration. Various forms of organizational frameworks have been proposed to accomplish this integration 
whilst maintaining certain levels of autonomy for the individual operators [20, 5, 21].

${ }_{85}$ However, the question of which particular systems to include in an effective MaaS offering has not been addressed yet ${ }^{1}$ Moreover, it is still unclear, to what extent they could even substitute current line-based public transport services [5].

Various new mobility services have emerged in the past years, ranging from dynamic 90 ride-pooling services like Vid $\left.\right|^{2}$ in New York City to electric bike-sharing like Smid $\left.\right|^{3}$ in Zurich. Given the novelty and variety of such schemes, there is only limited knowledge about their overall impacts on the transport system. Moreover, insights gained for one scheme cannot necessarily be transferred to others. For example, it has been established that station-based (round-trip) car-sharing schemes leverage a reduction in their mem-

${ }_{95}$ bers' vehicle ownership and vehicle miles traveled [2]. For free-floating car-sharing, such impacts were found to be substantially weaker, because this structually different service attracts other user groups and usage patterns [9]. Also for ride-hailing, Rayle et al. 8 found the user types and demand patterns to be different from taxi riders. Moreover, differences do not only appear between schemes, but also between cities. For example,

100 Fishman et al. [16 suggest that the ecological impact of bike-sharing strongly depends on city characteristics. They found that while bike-sharing may help to reduce $\mathrm{CO}_{2}$ emissions in car-centered cities, they may even trigger an increase in transit-oriented cities. Also, such schemes will likely be used differently when integrated with public transportation: As shown by Wang and Ross 22 for the case of New York City, taxi 105 trips made in connection with a public transport trip are typically shorter and are done by lower income users than point-to-point taxi trips. However, there have hardly been any empirical results on the interrelations between the different emerging mobility services yet.

110 Instead, simulation-based and game-theory approaches have mostly been used to study interactions of emerging modes. For example, 23] modeled a MaaS scheme offering first/last mile services. Their results reveal the existence of stable local optima for fleet sizes and fares. Those findings extend earlier research by Li and Quadrifoglio 24, who define critical demand levels below which demand-responsive services serve demand more efficiently. Generalizing these insights to maximizing social welfare instead of minimizing operational costs, Kim and Schonfeld [25] presented an approach to define a welfare threshold between conventional and flexible services in systems with multiple dissimilar regions. The welfare-centric approach was also supported by Qiu et al. [26, who suggest that minima of monetary cost may not correspond to a transport system-level optimum 120 given that also MaaS fleets contribute to road congestion. For the case of ride-sourcing schemes, Zha et al. 27] even found that a welfare-optimum state could only be reached if competitors were forced to merge and subsequently be regulated.

For the case of shared mobility, optimization has mostly been performed with respect to profit. Jorge and Correia [28 and Li et al. 29] provide an overview of such approaches, which mostly addressed fleet sizes, station locations, service areas, reservation policies

\footnotetext{
${ }^{1}$ Aiming for maximum attractiveness, Mulley 18 suggests to include all available modes.

2 https://ridewithvia.com/

3 https://www.smide.ch/
} 
or relocation strategies for car-sharing services. Similar approaches have been developed for bike-sharing [30]. However, most of such optimization approaches have substantial limitations, such as a small study area, no load-dependent travel times or fixed demand. Moreover, the individual emerging modes have usually been studied in an isolated manner. To address those limitations, Ciari et al. 31] simulated free-floating car-sharing as part of the transport system using the agent- and activity-based transport simulation MATSim 32. In particular, this allows to study substitution effects with other modes (private car, schedule-based public transport, bike and walk). Although this approach does not allow mathematical optimization of a target function, it allows to perform a scenario-based analysis to identify plausible, near-optimal solutions. Also, MATSim has recently been extended to model automated taxi services [33.

In this research, MATSim is further extended to allow a first joint simulation of large scale car-sharing, electric bike-sharing and ride-sourcing schemes to study their interactions with each other as well as with the existing transport system. Also, a potential integration with line-based public transportation including a subsidy framework is tested. The various scenarios are then used to understand, how a large-scale MaaS service could contribute to welfare and resource efficiency of the transport system. This way, the po145 tential efficiency gains of the strategic and operational integration aspect of MaaS (step 1) are studied, assuming that the integrated user interface (step 2) already is in place.

The approach is applied to the greater Zurich area. Zurich presents a special case, because it not only has a highly-developed public transport network reaching a $32 \%$ mode share $4^{4}$ In addition, a number of conventional and electric bike-sharing schemes as well as an electric scooter sharing scheme have been launched in the recent years, complementing the already existing station-based car-sharing scheme called Mobility ${ }^{5}$ Also Uber is already present in the market with its UberX, UberBlack and UberGREEN services. Hence, Zurich already is a test-lab for diverse emerging mobility services, none of which, however, is integrated with the public transport providers.

${ }^{4}$ for trips within the city of Zurich, according to Planungsbüro Jud (2012) Städtevergleich Mobilität https://skm-cvm.ch/cmsfiles/130124_stadtevergleich_mobilitat.pdf

https://www.mobility.ch/en/ 


\section{Methodology}

In this research, the agent-based microsimulation tool MATSim [32] is used to simulate MaaS services in the city of Zurich. In MATSim, a synthetic population of agents aims to pursue their desired daily activities whilst trying to minimize their generalized cost of travel. A key advantage of MATSim is that it offers a dynamic demand response towards changes in service attributes such as travel times or costs. Agents have pre-defined levels of mobility tool ownership (cars, season tickets and car-sharing membership), which reflect the current distribution in the local population. In the standard model, cars, public transport (timetable-based and routed), bike and walk are available modes. For this research, car-sharing services are added using earlier work of [34, 35, 36 and a plugin for autonomous taxis 33 is used to simulate ride-hailing services. In addition, a framework to simulate free-floating electric bike-sharing services was implemented for this research. To the authors' best knowledge, this is the first time that these different modes of shared mobility are jointly simulated not only in MATSim, but in any agent-based model.

\subsection{Implementation of Shared Modes}

All shared services are simulated on a microscopic level. Hence, the number of available vehicles (supply) is both limited and time- and space-dependent. For bike-sharing and car-sharing trips, agents identify the closest available vehicle, which they subsequently access by walk. The trip is routed on the congested network (car-sharing only). At the end of the trip, the shared bike or car is parked at the agent's destination. Availability of vehicles at the trip start time is recorded to inform re-planning decisions in the following iterations (see below for details). A detailed presentation of the car-sharing framework is provided in [36. The implementation of the bike-sharing framework is described in Appendix A. Agents using the ride-hailing service wait at their origin to be picked up by the closest available ride-hailing vehicle. The actual waiting time is stored and used in the later iterations to estimate the expected waiting time at the specific location. After being picked up, the agent is driven on the congested network to its destination, where it is dropped off. The vehicle remains at the drop-off location until it is dispatched to serve a new customer. Details are provided in [33].

Although MATSim allows to assign membership in shared modes to specific subgroups of agents, in this research it is assumed that all agents have access to all (shared) modes, irrespective of any memberships ${ }^{6}$ Following general practise, car-sharing and electric

190 bike-sharing are only considered available for agents holding a driver's license. Shared modes are available for all trips within a pre-defined service area. In this research, the service area covers the city of Zurich as well as a small belt around it (including the airport). The service area is shown in Figure 1. The area has around 380000 residents of which about 280000 hold a drivers license. Initial positions of bike-sharing, car-sharing 195 and ride-hailing vehicles were drawn randomly from the population density distribution within the service area.

\footnotetext{
${ }^{6}$ For most free-floating schemes, this is already the case given that they only charge a small registration fee. For ride-hailing services users can usually sign up for free.
} 


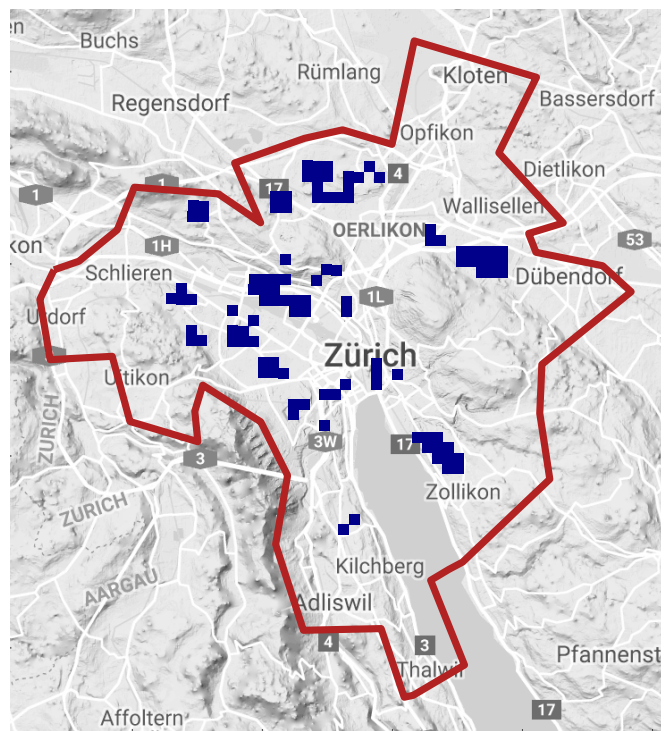

Figure 1: Service area for shared modes. Blue zones denote areas eligible for subsidies (see Section 4 for details).

Fares are based on current implementations of free-floating car-sharing, free-floating ebike-sharing and ride-hailing in Switzerland and are calculated as follows:

- Car-sharing: $0.38 \mathrm{CHF} / \mathrm{min} \cdot t$

- Bike-sharing: $0.25 \mathrm{CHF} / \mathrm{min} \cdot t$

- Ride-hailing: $\max \{6.0 \mathrm{CHF} ; 3.0 \mathrm{CHF}+1.8 \mathrm{CHF} / \mathrm{km} \cdot d+0.3 \mathrm{CHF} / \mathrm{min} \cdot t\}$

where $t$ is the travel time in minutes and $d$ is the in-vehicle distance in kilometers. Of course, larger fleet sizes and integration with other (shared) modes may result in different fares. However, to limit complexity, fares were assumed fixed in this research.

As a comparison: public transport fares in MATSim are $0.36 \mathrm{CHF} / \mathrm{km}$, with season tickets reducing this fare by $50 \%$ or $100 \% .7$ For car trips, a marginal cost of $0.27 \mathrm{CHF} / \mathrm{km}$ is assumed following [37. This value does not include any fixed cost (not considered in MATSim), but only the perceived cost of car travel relevant in mode choice.

\subsection{Mode Choice}

The MATSim simulation follows an iterative process, in which after each iteration, a certain number of agents are allowed to change their mode and/or route to reduce their generalized cost of travel (re-planning). At this stage, a trip-level mode choice model is

\footnotetext{
${ }^{7}$ Hence, the simulation does not exactly model the zone-based fare system, which actually is in place. Instead, fares are broken down into marginal cost while roughly maintaining the same level of average fares.
} 
used to calculate the utility of all trips throughout the simulation day. Unfeasible mode chains (e.g. car - transit - car) are dropped and one of the remaining chains is drawn based on the chain utility 33 .

To the authors' best knowledge, no mode choice models exist yet, which cover all seven modes simulated in this research. Therefore, mode choice parameters are based on a recent stated-preference experiment on automated vehicles [37, 38. The general form of the utility for mode $m$ is:

$$
\begin{gathered}
U_{m}=\alpha+\beta_{t t, m} \cdot t t_{m}+\delta_{m=\text { cycling }} \cdot \beta_{\text {age }} \cdot(\text { age }-18)+ \\
\beta_{\text {access }, m} \cdot \text { tacc }_{m}+\delta_{m=P T} \cdot \beta_{\text {transfers }} \cdot \# \text { transfer } s_{m}+ \\
\beta_{\text {cost }, m} \cdot\left(\frac{d i s t}{40 \mathrm{~km}}\right)^{\lambda} \cdot \text { cost }_{m}
\end{gathered}
$$

Since the mode choice model described in 37. does not include services like bikesharing, car-sharing and ride-hailing, the respective mode choice parameters were defined as follows: For the valuation of travel time of bike-sharing and car-sharing, the 215 respective parameters for bike and car were used. For ride-hailing, half of the value for public transport was used to account for the increased level of comfort and privacy. For all shared modes, access walk parameters were assumed to be equal to public transport. Waiting time for ride-hailing was assumed $50 \%$ of the corresponding parameter for public transport (motivated by [39]).

Alternative-specific constants were used to calibrate the number of daily rentals per vehicle in the base case. For free-floating car-sharing around 5 rentals per vehicle are assumed for small fleet sizes (compare [40]). For bike-sharing 6-8 rentals per vehicle were assumed realistic for Zurich 8 Finally, based on taxi data from New York City, up to 35-40 daily rentals per vehicle were assumed realistic for a highly utilized scheme $?^{9}$ All resulting mode choice parameters used in this research are summarized in Table 1 .

\begin{tabular}{|c|c|c|c|c|c|c|c|}
\hline & Walk & Bike & Car & $\mathrm{PT}$ & FFCS & FFBS & Ride-hailing \\
\hline constant & 0.431 & 0.344 & 0.827 & & -0.300 & -0.300 & -0.300 \\
\hline travel time [min] & -0.141 & -0.080 & -0.067 & -0.019 & -0.067 & -0.080 & -0.010 \\
\hline age $(>17)$ & & -0.049 & & & & -0.049 & \\
\hline access walk [min] & & & & -0.080 & -0.080 & -0.080 & \\
\hline waiting time [min] & & & & -0.038 & & & -0.019 \\
\hline number of transfers & & & & -0.170 & & & \\
\hline $\operatorname{cost}[\mathrm{CHF}]$ & \multicolumn{7}{|c|}{-0.126} \\
\hline$\lambda$ & \multicolumn{7}{|c|}{-0.400} \\
\hline
\end{tabular}

Table 1: Mode choice parameters for conventional modes (left) [37] and assumptions for shared mobility (right).

8 https://edition.cnn.com/travel/article/bike-share-boom-global-report/index.html gttp://toddwschneider.com/posts/taxi-uber-lyft-usage-new-york-city/ 


\subsection{Cost Structures}

To allow economic analysis of the schemes, their respective cost structures were estimated using the framework of [19. The values are presented in Table 2, Fixed and variable vehicle cost for car-sharing and ride-hailing are derived from 19 for the case of conventional midsize vehicles operated as a shared fleet. For ride-hailing, the variable vehicle cost is increased by $15 \%$ compared to car-sharing to account for empty rides [19. For bike-sharing, fixed cost were assumed to equal the retail price of the cheapest Stromer e-bike, minus $25 \%$ discount, written off over 5 years with 200 business days per year. This roughly corresponds to the current system characteristics of the local e-bike sharing scheme Smide in Zurich. For the variable costs, a product test revealed maintenance cost of $0.135 \mathrm{CHF} / \mathrm{km}$ for private customers, off which $25 \%$ discount was subtracted for larger fleets (economies of scale) ${ }^{10}$. Overhead and management cost were used from [19, but reduced by $50 \%$ for e-bikes ${ }^{11}$ For ride-hailing services, it is assumed that each vehicle is driven for 14 hours with a gross salary of $30 \mathrm{CHF} / \mathrm{h}$.

Table 2: Cost structures of Shared Mobility Services.

\begin{tabular}{l|rrr}
\hline & Bike-Sharing & Car-Sharing & Ride-Hailing \\
\hline fixed vehicle cost (CHF per veh. / day) & 4.1 & 8.5 & 8.5 \\
variable vehicle cost (CHF per km) & 0.101 & 0.223 & 0.256 \\
overhead \& management cost (CHF per veh. / day) & 7 & 14 & 14 \\
driver's salary (CHF per veh. / day) & & & 420 \\
\hline
\end{tabular}

\subsection{System-level analyses}

To allow an evaluation of the system-level impacts of the MaaS services, all scenarios are evaluated with respect to three key objectives:

- total network travel time: sum of travel times of all trips

- generalized cost: sum of the (dis-)utility of all performed trips (c.f. Equation 1), to which profits or losses of shared mobility operators as well as subsidies paid for public transport services are added. For private car travel, the full costs are considered in all cases 12

- total energy consumption: distance of all trips multiplied with an energy consumption factor. For private cars, an average gasoline consumption of $6.5 \mathrm{l} / 100 \mathrm{~km}$ was assumed ${ }^{13}$ Car-sharing vehicles operating in Basel and Geneva are VW up with an official consumption of $4.1 \mathrm{l} / 100 \mathrm{~km}$. For electric bikes, a consumption of $1 \mathrm{kWh} / 100 \mathrm{~km}$ is assumed ${ }^{14}$. For public transport, the total energy consumption

\footnotetext{
10 https://www.ktipp.ch/artikel/d/e-bikes-pannen-trueben-den-fahrspass/

${ }^{11}$ Bike-sharing schemes usually supply more bikes per member, so that user administration cost per bike is lower (compare 41). In addition, bikes are easier to collect when service is required.

${ }^{12}$ For Scenario 1 , the hidden cost was added to the disutility.

${ }^{13}$ for fuel consumption data for new car registrations compare http://www.verbrauchskatalog.ch/ de/informationen/verbrauch

${ }^{14}$ compare https://wWw.stromerbike.com/en_INT/e-bikes/st5.html 
reported by the local bus and tram provider was used 15 . Fuel consumption was 255 converted into energy using energy values of $9.7 \mathrm{kWh} / \mathrm{l}$.

For the system-level analyses, all trips conducted within the service area (compare Figure 1) are considered. 


\section{Scenarios}

The main goal of this research is to study, how a large-scale MaaS system could help to increase efficiency of the transport system. To this end, walk, bike, private car, public transport, electric bike-sharing, car-sharing and ride-hailing are all available to agents at their marginal cost. This way, mode choice is assumed unbiased from fixed / sunk costs, theoretically yielding more optimal results.

265 Hence, no subscriptions are considered for any of the shared modes. Only for public transport, season tickets are still in place. For the private car, only marginal costs are considered. Here, two cost levels were analyzed: First, the marginal cost of car travel was set to the currently perceived costs $(0.27 \mathrm{CHF} / \mathrm{km})$, while in a second step, the full costs according to [19] are assumed relevant for the agents' mode choice decisions (0.64 $270 \mathrm{CHF} / \mathrm{km})$,

Since the impact of shared mobility schemes may depend on their respective fleet sizes, different scenarios have been defined covering all combinations of the set fleet sizes:

- Car-sharing: 0, 250, 1000,4000

- Bike-sharing: 0, 250, 1000,4000

- Ride-hailing: 0, 250, 500, 1000,5000

The fleet sizes were chosen to cover all possible implementations from small fleets towards multiples of today's number of vehicles. For example, Uber claims to have 2500 drivers at their service across all of Switzerland as of July 2018 $8^{17}$. Moreover, about 1800 shared bikes were available in the city of Zurich in early $2018^{18}$. Free-floating car-sharing is currently not available in Zurich, however, in other Swiss cities schemes operate with up to 150 vehicles ${ }^{19}$ Fleets smaller than 250 vehicles were not simulated for computational reasons 20

In the first part of the analysis, impacts on transport system performance are studied for all combinations of fleet sizes using the perceived costs for private cars (Scenario 1). Second, the analysis is repeated for the full cost of private cars (Scenario 2). Each of the scenarios is then evaluated with respect to total generalized cost, total network travel times and total energy consumption.

\footnotetext{
${ }^{16}$ In this context, the full cost include acquisition cost, fuel, vehicle maintenance, insurance, taxes, administration and any other expense related to private car ownership and use.

17 https://www.nzz.ch/schweiz/chef-von-uber-schweiz-haelt-fest-fahrer-wollen-nicht-angestellt-sein-ld. 1403722

10 https://www.nzz.ch/zuerich/publibike-lanciert-den-heissen-zuercher-mietvelo-sommer-ld. 1374926

${ }^{10}$ https: //www.catch-a-car.ch/en/home/

${ }^{20}$ To limit computation time to a feasible level, only a $10 \%$ sample of the population was simulated in the model. While network capacities could be scaled down proportionally, this was not possible for shared mobility fleets. Here, only $10 \%$ of the fleet were simulated. While this approach has been widely used for medium to large fleets (compare [34, 35]), it may yield unreliable results for very small fleets.
} 
Yet, shared modes may not only increase system performance by complementing existing modes, but in certain situations, they may also represent an efficient substitute. To test this hypothesis, the 25 bus and tram lines operating in the city of Zurich with a fare recovery rate of less than $75 \%$ were removed ${ }^{21}$ This would amount to (hypothetical) savings of more than $200000 \mathrm{CHF}$ per day. In those areas, for which the distance to the next served public transport stop is increased by more than $50 \mathrm{~m}$ through this measure, use of shared mobility is subsidized as follows:

- subsidies are paid for any trip starting or ending in an eligible zone,

- ride-hailing trips are subsidized with $50 \%$ of the fare,

- those portions of bike-sharing or car-sharing fares, which exceed the corresponding public transport fare are subsidized by $100 \%$, i.e. travelers only pay rental charges up to the fare of the alternative (removed) public transport service.

To identify zones eligible for subsidies, the city was divided into $250 \mathrm{~m}$ grid cells. Figure 1 highlights the cells eligible for subsidies.

305

Of course, such a rough approach can only provide very first insights. In particular, it is well conceiveable that removing a public transport line will affect the productivity of various remaining lines. As a result, an optimal public transport network subject to the budget contraint stated above may likely look different.

${ }^{21}$ compare https://www.kantonsrat.zh.ch/Dokumente/Df49fc539-2ea1-4654-98df-68d694fec079/ R15301.pdf 


\section{Results}

More than 150 single scenarios were simulated in MATSim. For brevity, only a selection showing the key insights from the analyses is presented in this paper. The full set of results is available from the authors upon request.

In the following, Scenario 1 denotes all simulations, where the cost for private car travel was set to $0.27 \mathrm{CHF} / \mathrm{km}$, i.e. the perceived cost level. In Scenario 2, this value was set to $0.64 \mathrm{CHF} / \mathrm{km}$, which corresponds to the full costs.

\subsection{Competition of Shared Modes}

The first part of the analysis allows insights on the interactions and competition between the shared modes. To this end, Figure 2 shows the number of rentals for each shared mode.

The results indicate that for each shared mode in Scenario 1, there is a saturation effect for larger fleet sizes. Hence, despite increasing availability of the respective service, utilization of the vehicles drops after a certain point. The simulation results suggest optimal fleet sizes of around 1000 vehicles for car-sharing and bike-sharing, and at most 250 vehicles for ride-hailing. Yet, given the limited number of scenarios, the true optimal values may likely be higher or lower than indicated here.

330 The figure also provides insights into the competition between the shared modes. For example, it shows that demand for car-sharing and bike-sharing is affected by the fleet sizes of the other schemes. However, with a relative difference of $10 \%$, the demand impacts through competition are not substantial. Still, a certain pattern can be observed: presence of small car-sharing and ride-hailing fleets increases demand for bike-sharing,

335 whereas competition by large car-sharing fleets reduces it. In contrast, presence of a small bike-sharing scheme lowers demand for car-sharing, but larger bike fleets increase it. Interestingly, ride-hailing demand seems to be independent from competition of other shared modes.

340 Yet, presence of other shared modes in the market does not seem to substantially alter the structure of demand. Table 3 presents the access times and network distances. The standard errors are mostly less than $5 \%$ of the reported means. Also the trip distances are mostly independent of the fleet sizes of the different services. Only the access times are lower for larger fleets, with the strongest effect observable for ride-hailing with a $60 \%$ reduction in wait times when the fleet increases from 250 to 1000 vehicles.

Although trip distances are fairly constant throughout all scenarios, the spatial distribution of start locations varies substantially, as shown in Figure 3. For example with a small fleet size, bike-sharing start locations are quite concentrated to certain spots in the city center and the northern sub-center Oerlikon. When car-sharing and ride-hailing enter the market, the concentration is even more focused to the North, where the other services are less strong. Only at very large fleet sizes the distribution becomes more continuous and centered towards to city center. Also for car-sharing, demand is more disperse without competition. For small fleets and with competition, it is focused on the 

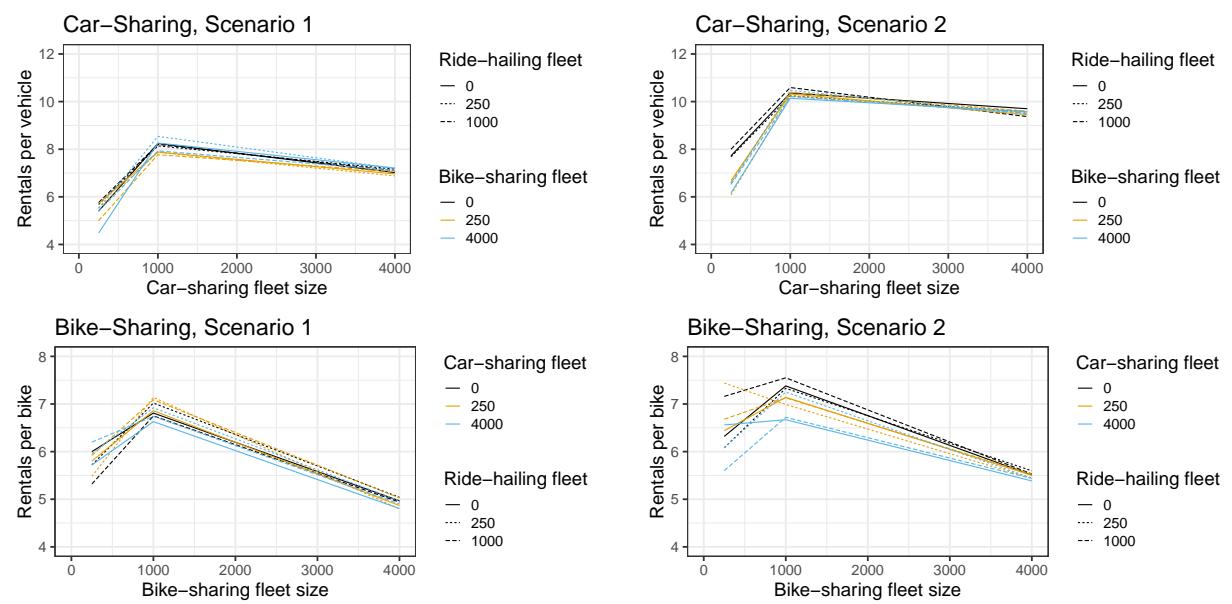

Car-sharing fleet

-0
$-\quad 250$
$-\quad 4000$

Ride-hailing fleet

-0
.- .250
--.1000

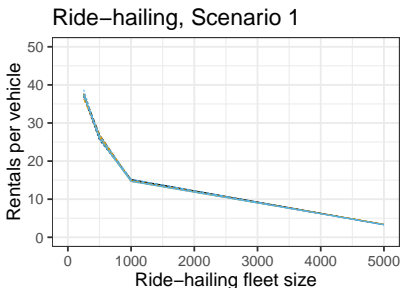

Bike-sharing fleet

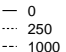

Car-sharing fleet

-0
$-\quad 250$

4000

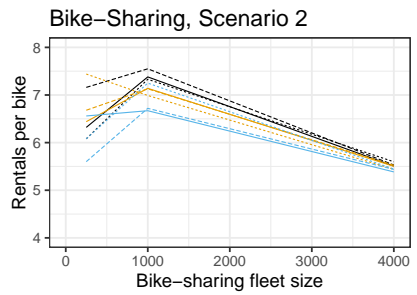

Car-sharing fleet

-0
$-\quad 250$
$-\quad 4000$

Ride-hailing fleet $\begin{array}{ll}-0 \\ -\cdots \\ \cdots . . & 250 \\ \cdots & 1000\end{array}$

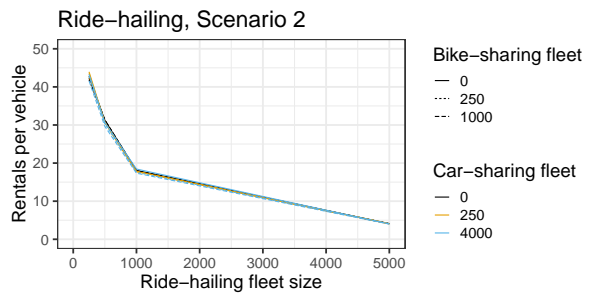

Figure 2: Number of rentals for shared modes

Table 3: Mean access times [min] and mean network distances [km] of trips. Access times are walk time for car- and bike-sharing and wait time for ride-hailing.

\begin{tabular}{ll|rrrr}
\hline Service & Fleet & \multicolumn{2}{|c}{ Access time [min] } & \multicolumn{2}{c}{ Trip distance [km] } \\
Scenario 1 & Scenario 2 & Scenario 1 & Scenario 2 \\
\hline Car-sharing & 250 & 3.64 & 3.71 & 4.61 & 5.06 \\
& 1000 & 3.47 & 3.50 & 4.52 & 5.09 \\
Bike-sharing & 4000 & 2.72 & 2.80 & 4.42 & 5.04 \\
& 250 & 3.66 & 3.63 & 1.83 & 2.31 \\
Ride-hailing & 1000 & 3.35 & 3.41 & 1.94 & 2.19 \\
& 4000 & 2.48 & 2.55 & 1.89 & 2.21 \\
& 500 & 9.16 & 9.46 & 3.49 & 3.70 \\
& 1000 & 5.23 & 5.56 & 3.44 & 3.65 \\
& & 3.69 & 3.74 & 3.44 & 3.66
\end{tabular}

355 city center, while larger fleet sizes lead demand to spread more into outer parts of the city. Interestingly, for case (b), car-sharing demand and bike-sharing demand appear to complement each other with demand peaks in different parts of the city. In contrast to bikeand car-sharing, ride-hailing demand follows a similar demand distribution throughout all scenarios. A reason for this may be that ride-hailing vehicles can move towards their

360 clients at higher speeds, increasing local availability of the service. For the same reason, car-sharing demand distribution approaches the one of ride-hailing for very large fleets. 
The results suggest that free-floating car-sharing and electric bike-sharing compete in the same market, whereas ride-hailing serves a different demand segment. However, the model cannot capture that car-sharing allows users to transport larger items, which is an important factor for a certain number of trips 9 .

Figure 3: Rental start locations for selected cases from Scenario 1.
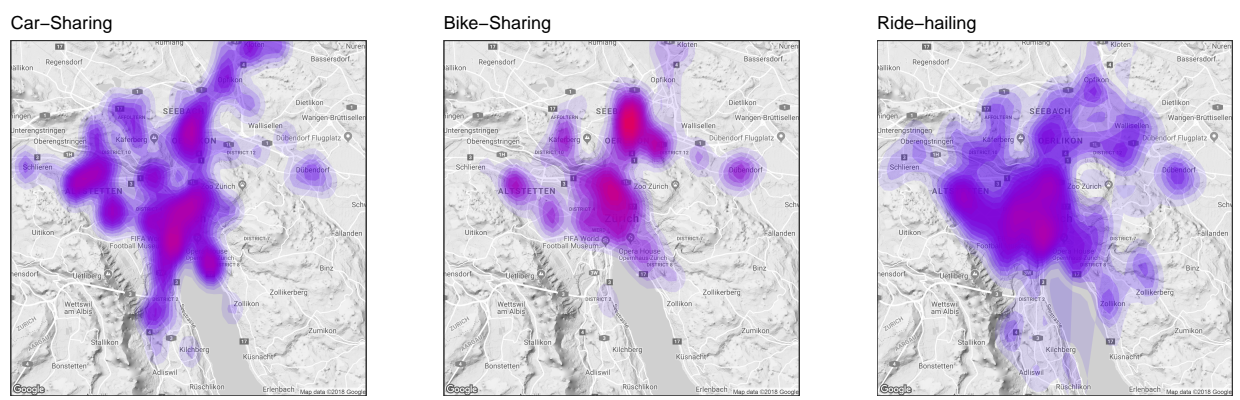

(a) Only one service operating in the area. Fleet size is 250 in each case.
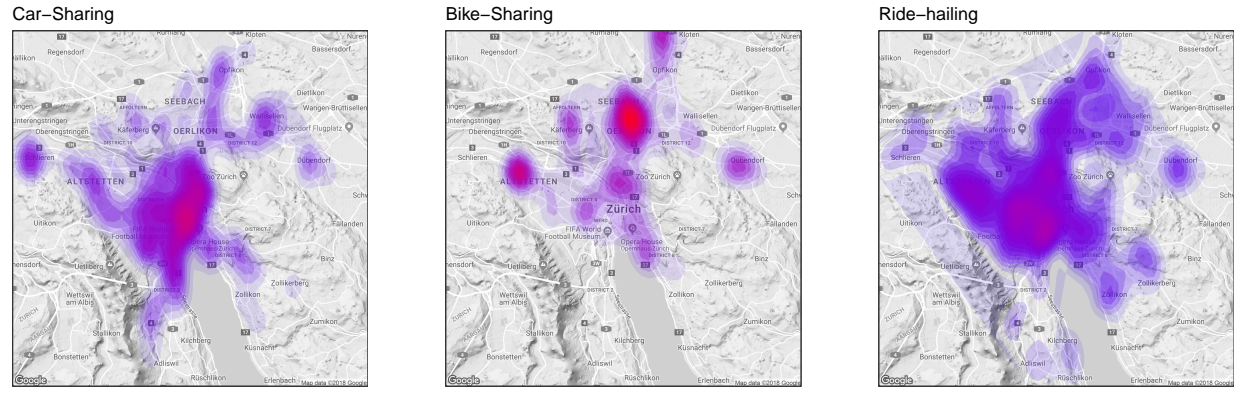

(b) Each service simultaneously operating with fleet size 250.
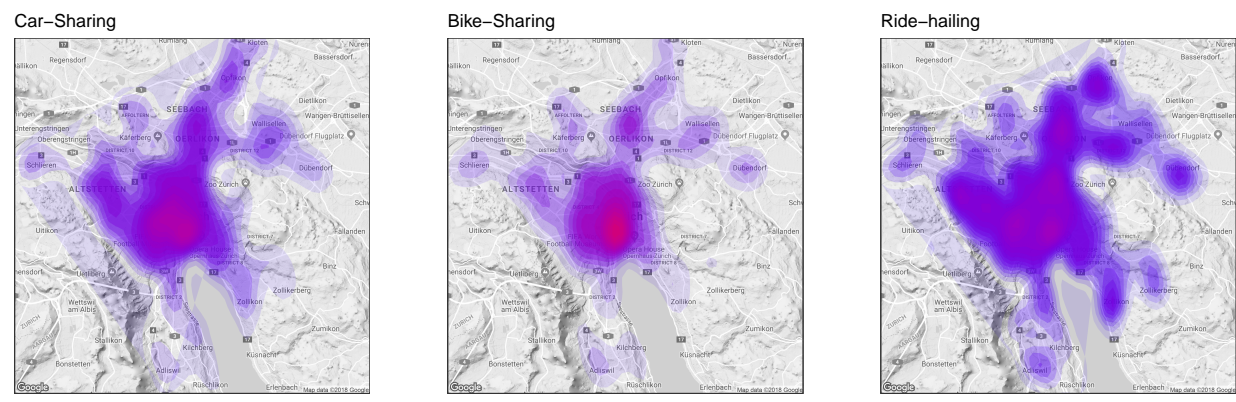

(c) Each service simultaneously operating with fleet size 4000 for car- and bike-sharing and 1000 for ride-hailing.

\subsection{Profitability of Shared Modes}

Using the fares and cost structures outlined in Section 3, the profit of each operator was determined for all scenarios. The results are presented in Figure 4. They indicate 
370 that in Scenario 1, none of the services can be operated at a profit. However, for carsharing and bike-sharing losses are only a few CHF per vehicle per day and are lowest for fleets of 1000 vehicles each. Interestingly, car-sharing profits are reduced in the presence of a small bike-sharing scheme (fleet size 250), whereas bike-sharing profits are reduced in the presence of a large car-sharing scheme (fleet size 4000).

375

For ride-hailing, operations are unprofitable in all scenarios with the smallest fleet size (250) being the least unprofitable with a loss of around $60 \mathrm{CHF}$ per vehicle per day. Here, losses are mostly driven by the high labor costs.
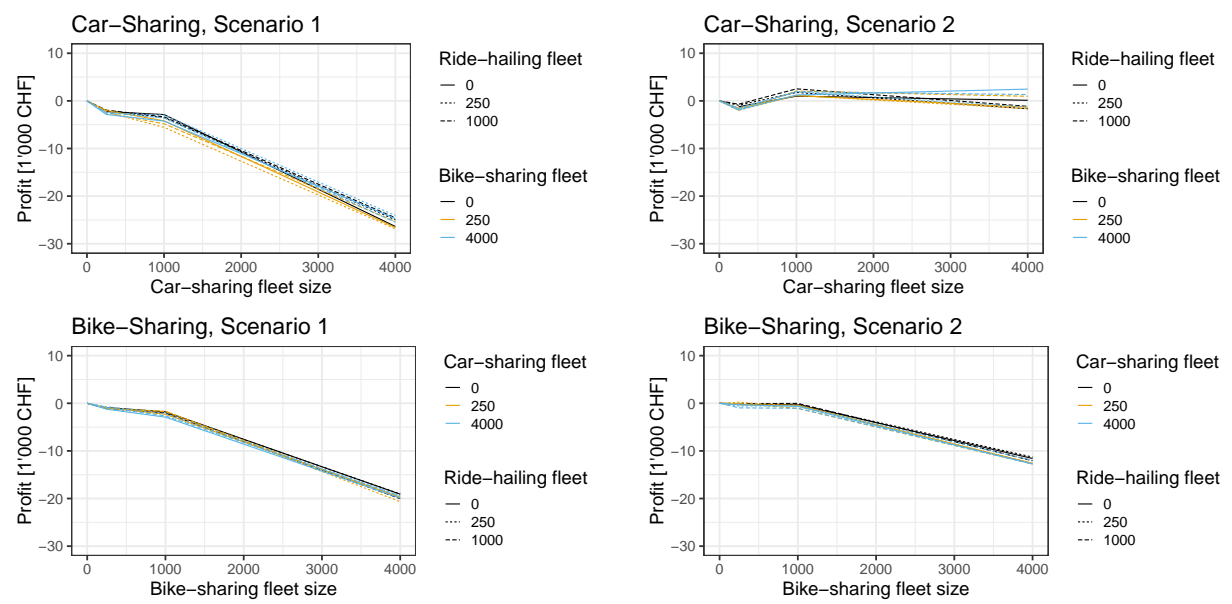

Car-sharing fleet

-0
$-\quad 250$
-

Ride-hailing fleet

-0
.- .250
--.1000

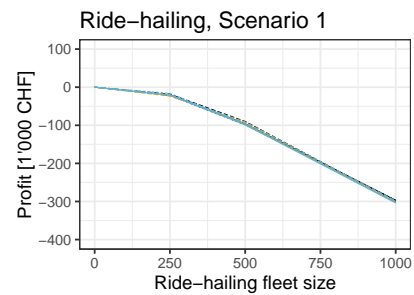

Bike-sharing fleet

-0
$-\cdots .250$

-.- 1000

Car-sharing fleet

-0
$-\quad 250$

\begin{tabular}{l}
-250 \\
$-\quad 4000$ \\
\hline
\end{tabular}

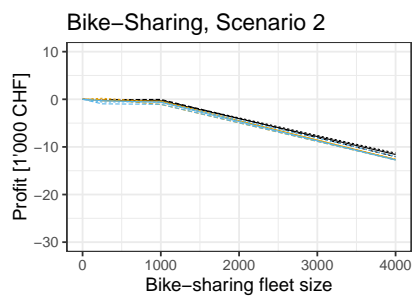

Car-sharing fleet

$-\quad 0$
$-\quad 250$
$-\quad 4000$

Ride-hailing fleet $\begin{array}{ll}- & 0 \\ \cdots . . & 250 \\ - & 1000\end{array}$

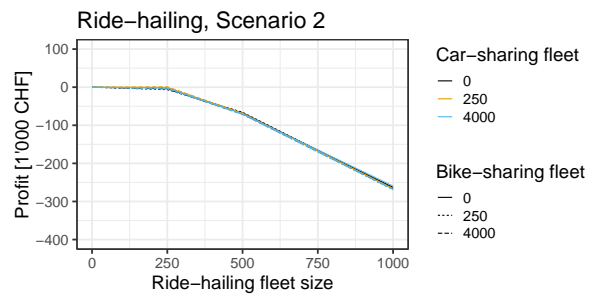

Figure 4: Revenue per day for shared modes

\subsection{Impact of full car cost in mode choice}

The results described above all refer to a case, in which shared modes were introduced into today's transport system. Yet, in the current situation, ownership of mobility tools causes a market segmentation into public transport users and car owners [1, leading to sub-optimal mode choice decisions. For private cars, the bias is most substantial, because agents only consider a part of the full car cost in their mode choice decisions. Therefore, all simulations were repeated in a Scenario 2, where costs for car travel were increased to $0.64 \mathrm{CHF} / \mathrm{km}$ ), thus including all costs related to car ownership and use ${ }^{22}$

\footnotetext{
${ }^{22}$ In this study, fares and subscriptions for public transport operations remain unchanged, because they are set politically and mostly aim at providing a basic level of accessibility for the respective area. Here, a more promising approach would be to prune the network as studied in Section 5.5
} 
As shown in Figure 2, increased costs for car-travel leads to a shift of demand towards shared modes. Car-sharing benefits the most with a $25 \%$ surge in the number of rentals. Ride-hailing sees an almost $15 \%$ increase, whereas bike-sharing demand only rises by about $7 \%$. Also trip distances are getting longer for all shared modes (especially carsharing and bike-sharing) to replace certain car trips. But despite the higher utilization, access times are only marginally longer.

The increased utilization has substantial impacts on the profitability of car-sharing and bike-sharing. In particular, daily losses for operating a fleet of 1000 share bikes plummet to less than $1 \mathrm{CHF}$ per bike. In case of a simulateous offering of car-sharing and ride-hailing with small fleets, even a profit of up to $0.8 \mathrm{CHF}$ per bike is reached. Yet, most profound impact can be observed for car-sharing. Here, the surge in demand allows for substantial daily profit of up to $3 \mathrm{CHF}$ per vehicle (for fleet size 1000). The strong increase in profitability for car-sharing can be explained by the high fixed costs (compare Table 2 of these services. For ride-hailing, a very small fleet of 250 vehicles can be operated at a daily profit of $20 \mathrm{CHF}$ per vehicle, but for larger fleet sizes, the balance turnes into a large loss.

\subsection{System-level analyses}

Judging from a system's perspective, operator profit is not necessarily the most important target function. Like for public transport, subsidizing such systems may be an interesting option if those schemes contributed to a more efficient transport system or to an increased level of accessibility. To this end, all scenarios were evaluated with respect to their impact on total travel time, total generalized cost and total energy consumption.

The results are presented in Figure 5. The upper plots show the total travel times and provide various key insights: First, introduction of shared modes (expecially carsharing) generally reduces travel times. Hence, despite the slow access walk towards 415 the next available vehicle, they offer a faster alternative than other modes. The effect is especially strong for car-sharing and ride-hailing. Second, full car cost (Scenario 2) would increase network travel times, which is the result of a mode shift away from the private car. Indeed, car mode share falls from $49 \%$ to $34 \%$ in the base case (without shared modes). And while the introduction of shared modes helps to reduce total travel time by up to $6 \%$, increasing car costs drive them up by about $15 \%$.

Yet, given that different modes provide different levels of comfort, travel times may not be the most important indicator of system performance. As described in Section 3 , a simple welfare measure has been used for this purpose: It includes the disutility of travel 425 for all trips (without fares paid for shared modes) as well as the operating costs of the shared services and subsidies paid for public transport operations. As shown in Figure 5 . the fleet size for car-sharing and ride-hailing (and the respective economic losses) are the key driver of the generalized cost. There is only marginal variation between the scenarios of different bike-sharing fleets. Generalized system cost are higher in Scenario 2, which 430 is mostly due to the longer total travel times (hidden car costs are included in the value for Scneario 1). 
In the optimal case for Scenario 1 (4000 car-sharing vehicles, 1000 shared bikes, 250 ride-hailing vehicles), generalized system cost is $4 \%$ lower than in the base case. For 435 Scenario 2 (4000 car-sharing vehicles, 4000 shared bikes, 250 ride-hailing vehicles) the reduction even amounts to $7 \%$ of the system cost. In various other cases, savings of a similar magnitude can be reached.

As a third measure, the impact on total energy consumption was analyzed. Here, all 440 trips with car, car-sharing, ride-hailing and electric bicycles were considered. For public transport the total energy consumption reported by the local tram and bus operator was used ${ }^{23}$ Interestingly, larger car-sharing and ride-hailing fleets reduce overall energy consumption, indicating that they do attract substantial demand from car or public transport. The most striking difference is between Scenario 1 and Scenario 2: Making

445 agents consider their full car cost already would help to reduce transport-related energy consumption by almost $25 \%$ (for trips within the service area). It is important to note that this analysis does not consider any grey energy or impacts on car-ownership, which were found to be the key drivers of the environmental impact of shared modes in earlier research [15.
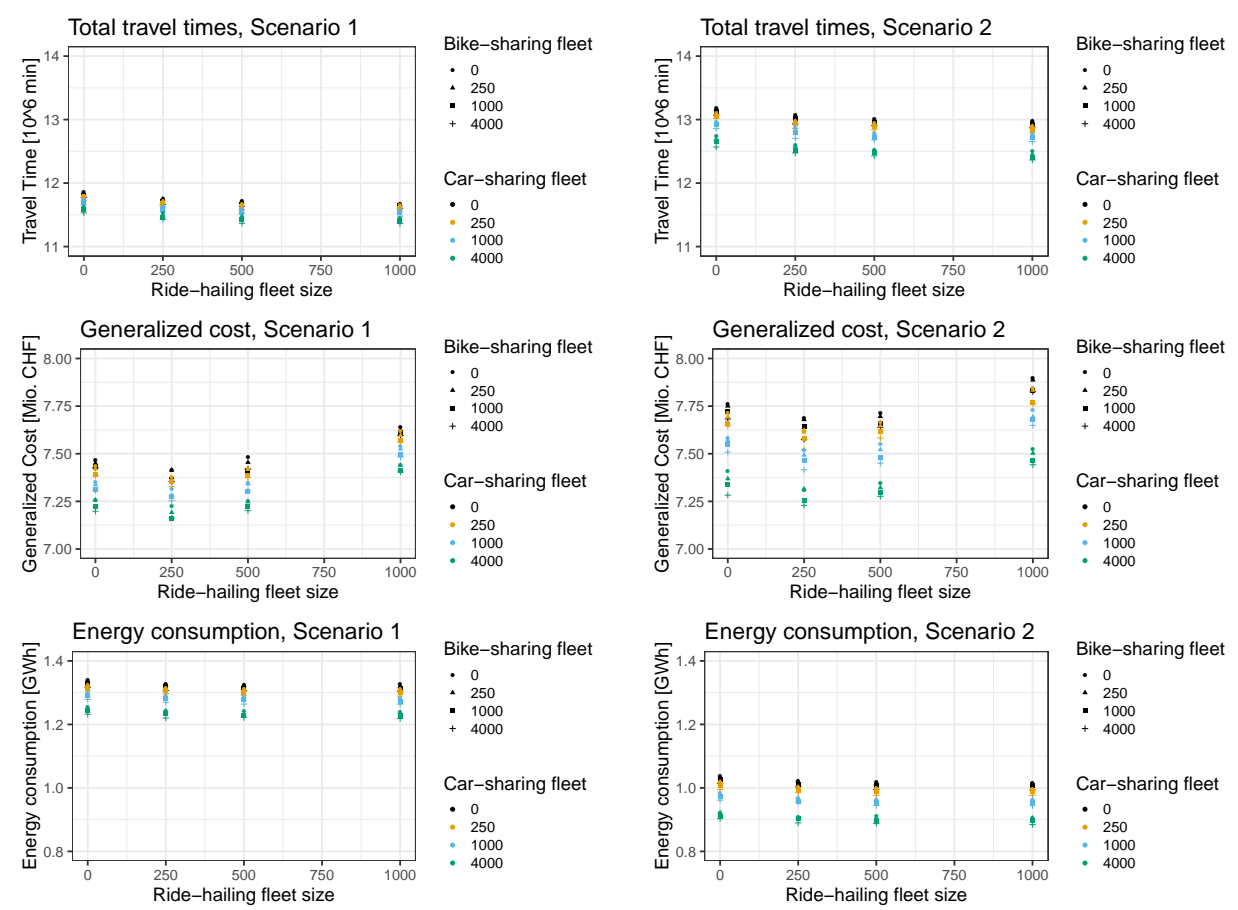

Figure 5: System-level analyses

\footnotetext{
${ }^{23} 129$ GWh in 2017 according to VBZ business report: https://www.stadt-zuerich.ch/vbz/de/ index/die_vbz/geschaeftsbericht.html
} 


\subsection{Public Transport Integration}

In Zurich, operation of various bus and tram lines are subsidized, to provide all parts of the city with a dense network of frequent public transport services. For the city alone, subsidies amount to more than 105 Mio. CHF per year ${ }^{24}$ Since shared modes can also be considered as part of public transport services, it is studied to what extent they could substitute highly subsidized bus and tram lines in providing accessibility towards lowerdensity areas. To this end, all 25 bus and tram lines with a fare recovery rate of less than $75 \%$ were dropped in return for subsidized offers of shared mobility (see Section 3 for details). To reduce computation time, only a selected number of cases was simulated for this analysis.

460

Obviously, the subsidies increase attractiveness of shared modes. As a result, the number of ride-hailing trips skyrockets by $55 \%$. Also, there are $22 \%$ more rentals of car-sharing vehicles and a $9 \%$ increase in bike-sharing use. As a result, ride-hailing becomes highly profitable in all cases (below 1000 vehicles) and car-sharing is profitable for a fleet size of 1000 vehicles. Bike-sharing generates a small profit only in Scenario 2. These results reflect the amount of subsidies for the different shared modes as presented in Tables 4 and 5. By far the most subsidies are paid for ride-hailing trips, whereas car-sharing and bike-sharing rides only attract a marginal share. Most importantly, in all cases the total amount of subsidies is lower than the amount currently paid for regular public transport services on the lines that were dropped (218400 CHF per day).

In most cases, this monetary gain comes at the expense of increased total travel times. However, the net impact appears to be positive and significant: As shown in Tables 4 and 5 generalized cost is up to $7 \%$ lower compared to the corresponding case with the 475 full public transport network. Compared to the base case (no shared mobility, full PT network), generalized cost can be reduced by up to $11 \%$.

The impact on energy consumption is even more substantial with a potential reduction of up to $20 \%$ when dropping the selected bus and tram lines ${ }^{25}$ Compared to the base case, 480 up to $31 \%$ reduction in total energy consumption are possible through a combination of all measures described above.

\footnotetext{
${ }^{24}$ Values are for 2013 and were published by the city's governing council in 2016: https://www. kantonsrat.zh.ch/Dokumente/Df49fc539-2ea1-4654-98df-68d694fec079/R15301.pdf

${ }^{25}$ Disaggregated data on energy consumption per bus line was not available. Therefore, the total energy consumption for public transport was reduced by $51.5 \%$, which corresponds to the share of the operating costs of the dropped lines among the total operating cost of all lines.
} 
Table 4: System-level analysis for base case and substitution case, where shared modes are subsidized to replace line-based public transport in certain areas. All numbers are for Scenario 1, i.e. mode choice depending on perceived car cost.

\begin{tabular}{lll||rr|rrr|rr}
\hline \multicolumn{3}{c}{ Fleet size } & \multicolumn{2}{c}{ Travel time $[1000 \mathrm{~h}]$} & \multicolumn{2}{c}{ Gen. cost [Mio. CHF] } & \multicolumn{2}{c}{ Energy [GWh] } & \multicolumn{2}{c}{ Subsidies [ kCHF] } \\
CS & BS & RH & base & subst. & base & subst. & base & subst. & CS+BS+RH \\
\hline 0 & 0 & 0 & 198 & 198 & 7.47 & 7.47 & 1.34 & 1.34 & 0.00 \\
250 & 0 & 0 & 197 & 198 & 7.44 & 7.43 & 1.33 & 1.18 & 0.69 \\
0 & 250 & 0 & 197 & 199 & 7.45 & 7.46 & 1.34 & 1.19 & 0.23 \\
0 & 0 & 250 & 196 & 196 & 7.41 & 7.26 & 1.33 & 1.18 & 26.39 \\
250 & 250 & 250 & 195 & 195 & 7.35 & 7.22 & 1.31 & 1.16 & 26.83 \\
1000 & 1000 & 500 & 192 & 191 & 7.30 & 7.02 & 1.28 & 1.11 & 41.88 \\
4000 & 4000 & 1000 & 189 & 186 & 7.40 & 6.95 & 1.22 & 1.03 & 65.07 \\
\hline
\end{tabular}

Table 5: System-level analysis for base case and substitution case, where shared modes are subsidized to replace line-based public transport in certain areas. All numbers are for Scenario 2, i.e. mode choice depending on full car cost.

\begin{tabular}{lll||rr|rrr|rr}
\hline \multicolumn{3}{c}{ Fleet size } & \multicolumn{2}{c}{ Travel time $[1000 \mathrm{~h}]$} & \multicolumn{2}{c}{ Gen. cost $[$ Mio. CHF] } & \multicolumn{2}{c}{ Energy [GWh] } & \multicolumn{2}{r}{ Subsidies [ kCHF] } \\
CS & BS & RH & base & subst. & base & subst. & base & subst. & CS+BS+RH \\
\hline 0 & 0 & 0 & 220 & 220 & 7.76 & 7.76 & 1.04 & 1.04 & 0.00 \\
250 & 0 & 0 & 218 & 220 & 7.71 & 7.72 & 1.02 & 0.88 & 0.90 \\
0 & 250 & 0 & 219 & 221 & 7.75 & 7.78 & 1.03 & 0.90 & 0.51 \\
0 & 0 & 250 & 218 & 218 & 7.69 & 7.55 & 1.02 & 0.88 & 34.07 \\
250 & 250 & 250 & 216 & 216 & 7.62 & 7.46 & 1.00 & 0.85 & 32.12 \\
1000 & 1000 & 500 & 212 & 211 & 7.48 & 7.18 & 0.96 & 0.79 & 53.08 \\
4000 & 4000 & 1000 & 206 & 201 & 7.44 & 6.91 & 0.88 & 0.71 & 76.67 \\
\hline
\end{tabular}




\section{Discussion}

The simulation results provide various insights on how Mobility as a Service (MaaS) and shared modes can help to increase efficiency of the transport system.

485

The paper presents a first joint simulation of three types of shared mobility: free-floating car-sharing, free-floating electric bike-sharing and ride-hailing. Although such schemes already co-exist in many cities around the globe, their interaction has hardly been studied yet. The simulation results show that for each of the shared modes, a critical fleet size

${ }_{490}$ is required to allow profitable operations. However, once a certain fleet size is reached, demand saturates. Hence, extremely large fleets of shared modes do not appear efficient (compare [10]). In addition, the results suggest that there is a twofold interaction between car-sharing and bike-sharing (and to a lesser extent ride-hailing): On the one hand, larger fleets of other shared modes result in competition on the level of single 495 trips. However, since agents plan their whole trip chain in advance, availability of, say, bike-sharing may guarantee a return trip, and thus enable a traveler to use car-sharing for the outbound trip. In fact, such behaviour has earlier been observed for car-pooling, where one of the deterrents is passengers' fear of getting stuck at their destination.

500 Moreover, the distributions of rental start locations suggest that car-sharing and bikesharing compete in a similar market: Both mostly serve the densest parts of the city, although demand for car-sharing reaches a bit further out (also longer trips). But also because of specific characteristics not modeled here (e.g. bicycles consume less space, but car-sharing vehicles are weather-prone and allow transport of larger goods 9]), they

505 should be seen as complements as long as barriers to use both schemes are not too large. In contrast, ride-hailing serves a different demand segment by connecting the outskirts of the city. However, some demand within the city center is taken away by car-sharing or bike-sharing.

510 The interpretation that the different schemes complement each other is also supported by the observation that the lowest generalized cost for the transport system is reached when all three schemes are present in the market. Capturing all monetary cost and disutility of travel, the generalized cost value can be considered a measure of efficiency of the transport system. In fact, simply by introducing shared modes, system efficiency can be increased by $4 \%$, which corresponds to a monetary equivalent of $300000 \mathrm{CHF}$ per day.

Interestingly, in the same system-optimal scenario, shared mobility operators generate a combined loss of $48000 \mathrm{CHF}$ per day. This raises the political question, whether operators of such systems should be subsidized (if they adjust their fleet sizes towards a system-optimal state). In fact, system-level benefits are even higher given the (up to) $3 \%$ reduction in energy consumption through shared modes.

The finding that in almost all cases, shared modes reduce system-wide energy consumption is particularly interesting. In the light of earlier research on bike-sharing [16, this means that to a substantial amount, shared modes substitute private car trips. It also supports an earlier study showing that free-floating car-sharing is mostly used for tangential trips and trips for which public transport service is poor [17]. In fact, energy 
impacts should be even higher given that car-ownership reductions (not modelled here) were found earlier to trigger even stronger behavioural change [15].

530

Moreover, simulation results indicate that shared modes can be a very efficient solution to substitute under-used bus services. Since the pruning of the network was done in a very rough manner, the actual efficiency gains of complementing a reduced line-based public transport network with subsidized modes of shared mobility. This insight will also be highly relevant to design public transport networks in an era of automated taxis, which can be operated at even lower cost [19].

Furthermore, the simulation results confirm the key expectation of Mobility as a Service (MaaS), i.e. that an integrated transport system in which services are offered at their marginal cost helps to increase system efficiency. To study this effect, all simulations in this paper were done twice: In Scenario 1, car-owners had a private car available for all trips at the generally perceived marginal cost $(0.27 \mathrm{CHF} / \mathrm{km})$. In Scenario 2, the cost attribute was increased to $0.64 \mathrm{CHF} / \mathrm{km}$, which captures the true cost of the trip (i.e. fixed/sunk cost were converted into marginal cost): This change alone triggered a reduction in transport-related eneroy consumption, because many travellers prefered other modes rather than paying the higher price for using a car. Yet, due to longer travel times of the alternative modes, total generalized cost are slightly higher for the case of "true" car prices.

${ }_{550}$ A next step would be to include externalities in the generalized cost, such as grey energy, GHG emissions, noise pollution or space consumption ${ }^{26}$ Also, the limited number of cases studied in this research does not allow to identify the optimal combination of different fleet sizes of shared modes, suggesting that the possible impacts may even be higher than reported here. Moreover, the current mode choice approach does not allow 555 inter-modal trips (e.g. using car-sharing as a feeder for public transport). Given the relatively small service area, this limitation will only lead to a small underestimation of demand for shared modes here, but needs to be addressed if larger areas were to be studied.

\footnotetext{
${ }^{26}$ Space consumption is only indirectly covered by parking cost included in the cost for car and carsharing.
} 


\section{Conclusion}

The key principle of Mobility as a Service (MaaS) is to allow travellers unbiased choice of modes for each trip. First field tests of MaaS schemes confirmed that in such a setup, test persons do make better choices, both saving money and reducing carbon emissions [4. The results of this research further support this notion by showing that simply by basing mode choice decisions on the full cost of private car travel, transportrelated energy consumption can be reduced by $25 \%$.

Moreover, results show that MaaS-impacts are even stronger when substantial fleets of car-sharing, bike-sharing and ride-hailing are introduced into the network. In fact, integration of shared modes may even allow substantial efficiency gains on the supply side, when used to provide accessibility to areas, in which demand is too low to support line-based public transportation. Combined with unbiased mode choice decisions, system efficiency can be increased by up to $11 \%$ and total energy consumption reduced by up to $31 \%$.

575 Given the limited number of cases studied in this research, the actual impacts may even be higher. However, it is still unclear how the lessons learned can be put into practise with difficult issues to be addressed both at the demand and at the supply side. For example, a new definition of public transportation is needed to include certain shared modes. Among other aspects, a measureable minimum level of service will have to be imposed if shared modes were to take over the role of public transportation in certain areas [5. Finally, more effective measures of taxation (or road pricing) will have to be developed to manage demand towards a more system-optimal state. 


\section{Acknowledgements}

This research was part of a Swiss National Fund project (National Research Program

71: Managing Energy Consumption, project number 407140_153807).

\section{References}

[1] H. Becker, A. Loder, B. Schmid, K. W. Axhausen, Modeling car-sharing membership as a mobility tool: A multivariate Probit approach with latent variables, Travel Behaviour and Society 8 (2017) 26-36.

[2] R. Cervero, Y. Tsai, City CarShare in San Francisco, California: Second-Year Travel Demand and Car Ownership Impacts, Transportation Research Record 1887 (2004) 117-127.

[3] J. Sochor, H. Strömberg, I. C. M. A. Karlsson, Implementing Mobility as a Service: Challenges in Integrating User, Commercial, and Societal Perspectives, Transportation Research Record 2536 (2015) 1-9.

[4] J. Sochor, I. C. M. A. Karlsson, H. Strömberg, Trying out mobility as a service: Experiences from a field trial and implications for understanding demand, Transportation Research Record 2542 (2016) $57-64$.

[5] D. A. Hensher, Future bus transport contracts under a mobility as a service (MaaS) regime in the digital age: Are they likely to change?, Transportation Research Part A 98 (2017) 86-96.

[6] R. Cervero, Mobility Niches: Jitneys to Robo-Taxis, Journal of the American Planning Association 83 (2017) 404-412.

7] M. Matyas, K. Kamargianni, Stated Preference Design for Exploring Demand for Mobility as a Service Plans, in: 5th International Choice Modelling Conference, Cape Town, 2017.

[8] L. Rayle, D. Dai, N. Chan, R. Cervero, S. Shaheen, Just a better taxi? A survey-based comparison of taxis, transit, and ridesourcing services in San Francisco, Transport Policy 45 (2016) 168-178.

[9] H. Becker, F. Ciari, K. W. Axhausen, Comparing car-sharing schemes in Switzerland: User groups and usage patterns, Transportation Research Part A 97 (2017) 17-29.

[10] F. Ciari, H. Becker, How disruptive can shared mobility be? A scenario-based evaluation of shared mobility systems implemented at large scale, Disrupting Mobility (2017) 51-63.

610 [11] K. W. Axhausen, P. Fröhlich, M. Tschopp, Changes in Swiss accessibility since 1850, Research in Transportation Economics 31 (2011) 72-80.

[12] A. Loder, Ambühl, M. Menendez, K. W. Axhuasen, Empirics of multi-modal traffic networks - Using the 3D macroscopic fundamental diagram, Transportation Research Part C 82 (2017) 88-101.

[13] C. Mulley, J. D. Nelson, Flexible Transport Services: A new market opportunity for public transport, Research in Transportation Economics 25 (2009) 39-45.

[14] E. Fishman, S. Washington, N. Haworth, Bikeshare: A Review of Recent Literature, Transport Reviews 36 (2016) 92-113.

[15] S. A. Shaheen, A. P. Cohen, Carsharing and Personal Vehicle Services: Worldwide Market Developments and Emerging Trends, International Journal of Sustainable Transportation 7 (2013) $5-34$.

[16] E. Fishman, S. Washington, N. Haworth, Bike shares impact on car use: Evidence from the United States, Great Britain, and Australia, Transportation Research Part D 31 (2014) 13-20.

[17] H. Becker, F. Ciari, K. W. Axhausen, Modelling free-floating car-sharing use in Switzerland: A spatial regression and conditional logit approach, Transportation Research Part C 81 (2017) 286299.

[18] C. Mulley, Mobility as a Service (MaaS) - does it have critical mass?, Transport Reviews 37 (2017) 247-251.

[19] P. Bösch, F. Becker, H. Becker, K. W. Axhausen, Cost-based Analysis of Autonomous Mobility Services, Transport Policy 64 (2018) 76-29.

[20] G. Ambrosino, J. D. Nelson, M. Boero, I. Pettinelli, Enabling intermodal urban transport through complementary services: From Flexible Mobility Services to the Shared Use Mobility Agency, Research in Transportation Economics 59 (2016) 179-184.

[21] G. Smith, J. Sochor, I. C. M. Karlsson, Mobility as a Service: Development scenarios and implications for public transport, Research in Transportation Economics.

[22] F. Wang, C. L. Ross, New potential for multimodal connection: exploring the relationship between taxi and transit in New York City (NYC), Transportation. 
[23] S. Djavadian, J. Y. J. Chow, An agent-based day-to-day adjustment process for modeling Mobility as a Service with a two-sided flexible transport market, Transportation Research Part B 104 (2017) $36-57$

24] X. Li, Quadrifoglio, Feeder transit services: Choosing between fixed and demand responsive policy, Transportation Research Part C 18 (2010) 770-780.

[25] M. Kim, P. Schonfeld, Maximizing net benefits for conventional and flexible bus services, Transportation Research Part A 80 (2015) 116-133.

[26] H. Qiu, R. Li, J. Zhao, Daily Level Dynamic Pricing in Shared Mobility-on-Demand Service, in: 97th Annual Meeting of the Transportation Research Board, Washington, D.C., 2018.

27] L. Zha, Y. Yin, H. Yang, Economic analysis of ride-sourcing markets, Transportation Research Part C 71 (2016) 249-266.

[28] D. Jorge, G. Correia, Carsharing systems demand estimation and defined operations: a literature review, EJTIR 13 (3) (2013) 201-220.

[29] Q. Li, F. Liao, H. J. P. Timmermans, H. Huang, J. Zhou, Incorporating free-floating car-sharing into an activity-based dynamic user equilibrium model: A demand-side model, Transportation Research Part B (107) (2018) 102-123.

[30] T. Raviv, M. Tzur, I. A. Forma, Static repositioning in a bike-sharing system: models and solution approaches, EURO Journal on Transportation and Logistics (2013) 187-229.

655 [31] F. Ciari, M. Balac, M. Balmer, Modelling the effect of different pricing schemes on free-floating carsharing travel demand: a test case for Zurich, Switzerland, Transportation (42) (2015) 413-433.

[32] A. Horni, K. Nagel, K. W. Axhausen, The Multi-Agent Transport Simulation MATSim, Ubiquity Press, London, 2016.

[33] S. Hörl, Agent-based simulation of autonomous taxi services with dynamic demand responses, Procedia Computer Science 109 (2017) 899-904.

[34] M. Balac, F. Ciari, K. W. Axhausen, Carsharing demand estimation: Zurich, Switzerland, area case study, Transportation Research Record (2536) (2015) 10-18.

[35] M. Balac, F. Ciari, K. W. Axhausen, Modeling the impact of parking price policy on free-floating carsharing: case study for Zurich, Switzerland, Transportation Research Part C (77) (2017) 207225 .

[36] M. Balac, H. Becker, F. Ciari, K. W. Axhausen, Modeling competition between free-floating carsharing operators - a case study for Zurich, Switzerland (2018).

[37] F. Becker, Mode choice models for MATSim (2018).

[38] S. Hörl, M. Balac, K. W. Axhausen, A first look at bridging discrete choice modeling and agentbased microsimulation in MATSim, Procedia Computer Science 130 (2018) 900-907.

[39] C. Frei, M. Hyland, H. S. Mahmassani, Flexing service schedules: Assessing the potential for demand-adaptive hybrid transit via a stated preference approach, Transportation Research Part C 76 (2017) 71-89.

[40] S. Habibi, F. Sprei, C. Englund, S. Pettersson, A. Voronov, J. Wedlin, H. Engdahl, Comparison of free-floating car sharing services in cities (2017).

[41] J. Zhao, W. Deng, Y. Song, Ridership and effectiveness of bikesharing: The effects of urban features and system characteristics on daily use and turnover rate of public bikes in China, Transport Policy (35) (2014) 253-264. 


\section{Appendix A. Bike-Sharing Module}

Free-floating bike-sharing service for this study is implemented in a similar manner as the free-floating car-sharing service [36. The fleet of bicycles is available for rental in the service area defined by a shapefile. Upon departure from an activity, agents reserve the closest available bike, which thus becomes unavailable to other customers. The agent is then routed on the shortest path in the road network with a constant speed of $14 \mathrm{~km} / \mathrm{h}$ After finishing the bike-sharing trip, the agent leaves the bike at the destination facility, where the bike becomes available to other customers.

An important limitation of the current framework is that it does not consider re-charging of the electric bicycles. In the current bike-sharing scheme in Zurich, this is addressed

690 by both providing customers with bonuses if ending their trip at a charging station and by collecting bicycles with empty batteries to re-charge them. Optimizing this process would require substantial further work, which is out of the scope of this research. For the results presented here, this limitation means that there is a slight underestimation in operating costs and a marginal overestimation in demand.

695

Information on all rentals is gathered throughout the mobility simulation and stored in the output directory for analyses. Recorded information includes access time, trip duration, bike used, origin coordinate and destination coordinate. Information on bicycle availability and access times is also recorded in 15 min time bins for $\mathrm{km}^{2}$ zones during the simulation. In the subsequent iteration, to inform mode-choice decision in the subsequent iteration.

\footnotetext{
${ }^{27}$ This corresponds to average speeds observed at the local electric bike-sharing scheme Smide in Zurich.
} 